\title{
Canadian patients with chronic hepatitis B cannot access appropriate drug treatments: A call for change
}

\author{
Morris Sherman MB BCH PhD FRCPC 1 , Samuel S Lee MD FRCPC ${ }^{2}$
}

\begin{abstract}
In 2007, the Common Drug Review (CDR) Committee decided not to recommend reimbursement for entecavir for the treatment of patients with chronic hepatitis B (CHB), except in those with cirrhosis. In 2009, tenofovir was approved with the same restriction. This had the effect of throwing the management of this disease in Canada into crisis. However, this is just a single step in a long history of official neglect, ignorance and bad decision making regarding this disease that has resulted in the management of $\mathrm{CHB}$ in Canada being on par with third-world countries.
\end{abstract}

Physicians treating CHB patients were left stunned and perplexed when the CDR recommendations were announced. The basis for this decision is not clear. There are no studies of management of hepatitis B virus (HBV) cirrhosis using either tenofovir or entecavir. In the published studies, the indication for treatment was either active hepatitis or high viral load (1-3) - cirrhosis did not figure into the treatment decision. Subgroup analysis of treatment studies of entecavir and tenofovir suggested that the response in patients with cirrhosis is no different from that in noncirrhotic patients. A major goal of management of HBV patients is to prevent the development of cirrhosis. Waiting until cirrhosis has developed and then treating the patient seems to be a classic example of 'locking the barn door after the horse has gone'. Allowing cirrhosis to develop increases the risk of developing hepatocellular carcinoma (HCC) from approximately $0.4 \% /$ year, to $4 \%$ to $8 \% /$ year $(4,5)$. Because death from HCC is the most common cause of death in patients with $\mathrm{HBV}$, and because approximately $20 \%$ to $25 \%$ of all subjects chronically infected with HBV will develop this complication (6), the decision of the CDR is inexplicable.

The pathogenesis of HCC in CHB lasts decades, most of it under the radar. It takes many years for a cell to accumulate all of the genetic and epigenetic changes required to develop HCC. Thus, allowing the carcinogenic process to continue untreated for years before instituting therapy defeats the objective of therapy.

The prevalence of CHB in Canada is unknown. Estimates of the prevalence of HBV infection are in the range of 240,000 to 600,000 people $(7,8)$. There are reasons to believe that the true prevalence is closer to the upper end of this range. This makes $\mathrm{CHB}$ more common in Canada than hepatitis $\mathrm{C}$, and much more common than HIV. Moreover, the prevalence will increase in the future because of immigration. Of the approximately 200,000 refugees and immigrants who come to Canada each year, the vast majority now originate from countries in east Asia, southeast Asia, west Asia (India-Pakistan region), Africa, Eastern Europe and Latin America (6). These are all either high-endemic regions (Asia [except west Asia] and sub-Saharan Africa) with a population prevalence of $\mathrm{HBV}$ of $7 \%$ to $17 \%$, or medium-endemic (most of Latin America, eastern Europe and west Asia) with HBV infection rates of $2 \%$ to $5 \%$. Our estimates suggest that the size of the HBV-infected population will increase by approximately 1000/year because of immigration (8). Universal vaccination against HBV will not have a major effect on the prevalence of HBV in immigrants coming into Canada for many years to come due to the late introduction of vaccination in countries such as China. Thus, we welcome immigrants from these areas of the world, but then refuse to provide them with the care they need for their CHB. Moreover, $\mathrm{CHB}$ is also prevalent in some nonimmigrant populations including northern Aboriginals, such as the Inuit and Dene people, sex-trade workers and 'street people'.

Despite these alarming figures, chronic HBV infection is not on any government - neither federal nor provincial - radar. There are a few programs in some provinces that attempt to deal with hepatitis C, but none for HBV, despite the fact that the diseases caused by the two viruses are identical. The federal government spends more than $\$ 40$ million annually on HIV programs. They claim to spend $\$ 10$ million on hepatitis $\mathrm{C}$ programs (a pitifully small amount), but nothing has been spent on HBV programs. Acute hepatitis B is a notifiable disease, but $\mathrm{CHB}$ is not. All positive HBV surface antigen tests are notified to the local health authorities, who follow-up contacts. If the patient has CHB rather than the acute form, positive tests are never collated and no attempt is made to remove duplicates. Thus, no one really knows how many HBV-infected individuals there are in Canada. Because there are no data, governments do not take notice.

As described above, the major consequence of $\mathrm{CHB}$ infection is HCC - the most frequent cause of death in patients with untreated hepatitis B. The demographics of the population of HBV carriers in Canada are such that the immigrant population is now reaching the age at which HCC becomes common (8). Indeed, HCC mortality is one of the fastest growing cancer-related mortalities in Canada, and here, unlike the United States, much of this is fueled by HBV.

Hepatitis B is a treatable disease; however, the reimbursement policies that most provincial governments have implemented will prevent the majority of patients from accessing treatment at an appropriate stage of their disease that will reduce - if not eliminate - the risk of liver cancer. A recent survey (9) confirmed that few provinces adhere to the Canadian HBV treatment guidelines (10) in their reimbursement policies and, as a consequence, many deserving patients are left untreated.

To understand the current problem with reimbursement of HBV antivirals, such as entecavir and tenofovir, requires some background. Lamivudine was the first and, for some years, the only nucleoside analogue to be approved for the treatment of CHB. The initial registration trials were of one years' duration. Yet, right from the start, it was apparent that lamivudine would be required for longer than that in most instances. However, because the pharmaceutical companies undertook studies of one years' duration for purely practical reasons, a year became the standard that governments would reimburse. Most require a new application each year.

Unfortunately, lamivudine turned out to be a poor drug in that antiviral resistance is common, reaching approximately $70 \%$ of patients after four to five years (11). Fortunately, there are two newer, very effective agents - entecavir and tenofovir - both of which have excellent efficacy and safety profiles, with very low to zero rates of resistance being reported. Thus, most expert consensus guidelines recommend that lamivudine no longer be used, and that first-line therapy should be a potent nucleoside or nucleotide analogue such as tenofovir, entecavir or telbivudine. Such guidelines have been issued

${ }^{1}$ Department of Medicine, University of Toronto, Toronto, Ontario; ${ }^{2}$ Department of Medicine, University of Calgary, Calgary, Alberta

Correspondence: Dr Morris Sherman, Department of Medicine, Toronto General Hospital, 585 University Avenue, Toronto, Ontario M5G 2 N2.

Telephone 416-340-4756, fax 416-591-2107, e-mail morris.sherman@uhn.on.ca

Received for publication July 27, 2011. Accepted August 14, 2011 
by the hepatology societies of all major global regions including Europe (12), the United States (13) and Canada (10). These guidelines also state that pegylated interferon alpha-2a (PEG IFN) for one year is indicated for the treatment of HBV. PEG IFN was not considered by the CDR, but its use is restricted in many provinces. For example, PEG IFN for HBV is not reimbursed in Ontario (not even for a six-month course) despite the fact that PEG IFN costs the same as standard IFN, which is reimbursed.

Adefovir, which was the second HBV antiviral to be introduced, is not as potent as either tenofovir or entecavir, and no longer has a place as first-line therapy. Although it is approved for the YMDD resistance mutation in some provinces, even this is outdated, and tenofovir is now the drug of choice for this indication (14). Adefovir was licensed in Canada in 2003; however, it was held up at the level of the Patented Medicine Price Review Board (PMPRB) for three years. Then the CDR refused to recommend adefovir for reimbursement. This meant that although there was effective therapy for lamivudine resistance, it would not be available in Canada for public reimbursement (approximately two-thirds of all patients). While other provinces either put restrictions on the use of adefovir or made no comment, British Columbia (BC) explicitly declined to list adefovir. However, after local organizations protested and embarrassed the government, the $\mathrm{BC}$ Minister of Health asked the CDR Committee to review adefovir again. The committee subsequently approved adefovir for lamivudine resistance, although there did not appear to be any new evidence on which the decision was based.

At approximately the same time the CDR Committee was reviewing telbivudine and entecavir, they completely rejected reimbursement for telbivudine and approved reimbursement for entecavir only for patients with cirrhosis. In 2009, a similar cirrhosis-only recommendation was made for tenofovir. Subsequently, provincial and territorial formularies, except in Quebec and Alberta, have followed the CDR guidelines. Quebec does not participate in the CDR process, and all HBV agents are available without restriction. In Alberta, only specialists in hepatology, gastroenterology and infectious disease can prescribe tenofovir and entecavir, but without other restrictions, ie, any HBV-infected patient can be treated according to clinical judgment.

The CDR recommendations on the use of tenofovir and entecavir make no sense. The CDR is supposed to make decisions based on hard end points, such as survival and cost efficacy, using survival as an end point. Although there is no level 1 evidence that treating HBV reduces the risk of $\mathrm{HCC}$ or increases survival rates, there is plenty of indirect evidence to support this notion. One randomized and several nonrandomized prospective and retrospective studies show that antiviral treatment reduces disease progression in $\mathrm{HBV}$, including a decrease in the incidence of HCC $(5,15-20)$. Studies have shown that the risk of HCC is directly related to viral load in patients older than 30 years of age $(5,18)$, and that treatment with antivirals reduces viral load. Thus, all available evidence points in the same direction - that treatment with antivirals reduces HCC incidence and mortality. Level 1 evidence of a reduction in mortality from HBV will never become available because it is considered unethical to perform a placebocontrolled trial. Thus, a stubborn insistence on level 1 evidence before approving tenofovir and entecavir for general use will result in thousands of unnecessary deaths from HCC. In the absence of level 1 evidence, we must rely on lesser degrees of evidence. We are not at liberty to ignore the message that the evidence appears to be providing. In addition, there are considerable data derived from decision analysis and cost-efficacy studies to support the use of entecavir or tenofovir as first-line therapy in patients with CHB (21-24).

In Ontario, the most populous province and almost certainly the province with the largest HBV-infected population (8), the situation is even worse. Patients younger than 40 years of age cannot access lamivudine unless cirrhosis is present. The basis for this restriction is not clear. There are no studies in which the outcome of disease has been stratified according to being older or younger than 40 years of age. This decision presumably represents an attempt to limit costs. In essence, this means that younger HBV-infected persons in Ontario cannot even access inferior therapy for their CHB. This, despite the evidence from cost efficacy analyses that treatment of $\mathrm{HBV}$ is cost effective and provides substantial improvements in survival (21-24). Thus, this is a false economy. There is no way that treating $\mathrm{CHB}$ is more expensive than providing treatment, including liver transplantation, for patients with HCC. In Ontario, patients who have been treated with lamivudine and who developed resistance to it were initially refused reimbursement of any additional treatment unless they had cirrhosis. This decision has been reversed, again, seemingly without any scientific evidence to have triggered the decision. This change of heart presumably means that government recognizes the importance of treating patients before the development of cirrhosis, but apparently the government believes that the possibility of lamivudine resistance only develops on your 40th birthday.

The irony is that, in Ontario, sorafenib is reimbursed for the treatment of liver cancer. Sorafenib provides on average two to three months of additional life, at a cost of $\$ 6000 /$ month. It is a mystery as to how this can be cost effective, whereas treating HBV with effective antivirals is not cost effective in the eyes of the Ontario Drug Benefit Formulary. The cost of one year of sorafenib is approximately equal to 10 years of antiviral therapy.

Beyond costs, however, there is a medical principle at stake. By limiting the use of tenofovir and entecavir only to patients with cirrhosis and insisting that lamivudine should be the only first-line treatment, the CDR and the Ontario Drug Benefit Formulary are recommending a strategy that will encourage the development of antiviral resistance. The development of antiviral resistance in HBV patients is not a trivial issue. Adefovir is not a very potent agent, and combined lamivudine/adefovir resistance has been described, even with optimal use of adefovir. Tenofovir has become the recommended agent for lamivudine resistance. Entecavir is not recommended as monotherapy for lamivudine resistance because of a high rate of entecavir resistance development $(13,25)$. Thus, with the development of lamivudine resistance, treatment options become very limited. Unlike HIV, we do not have a multitude of agents to choose from when resistance develops. Tenofovir resistance probably exists, but has yet to be characterized. We 'shoot ourselves in the foot', choosing a reimbursement policy that encourages the development of antiviral resistance.

Thus, bureaucratic bungling has deprived patients with HBV in Canada of the most effective therapy available. It is a national disgrace that this situation was allowed to develop, and is an indication of just how dysfunctional our drug approval process has become. Nowhere else is a drug required to pass through so many hoops to be made generally available. Health Canada licenses the drug, re-evaluating all of the data that the United States Food and Drug Administration and European Medicines Agency have evaluated. The drug must then pass through the PMPRB, which sets the price that the manufacturer can charge. There are several criteria that the PMPRB uses, none of which are unreasonable. However, where the PMPRB failed in the case of adefovir was in not recognizing that this was not just another lamivudine and, therefore, a price increase was justified. This delayed the approval of adefovir by approximately three years. The drug also undergoes review by the CDR Committee. The CDR has refused reimbursement to approximately $40 \%$ of the agents it has reviewed, and has restricted reimbursement for many others. Generally, if the CDR refuses reimbursement, the provinces will follow suit, but not always. Conversely, a 'yes' to reimbursement by CDR means 'maybe' to the provinces. There are examples of drugs refused reimbursement by the CDR that are funded in individual provinces and vice-versa for drugs approved by the CDR. After the CDR, some provinces have their own review process, in which the CDR recommendations are accepted or rejected. All of this takes time, so that it might be many months - even years - before a licensed drug is generally available with reimbursement. Neither the PMPRB nor the CDR Committee consulted with experts from the hepatology community when making decisions regarding these drugs. Instead, on the CDR committee, 
are an Alberta rancher and a retired high school principal. How is it that these people have opinions on the use of these drugs that are considered to be more informed than disease content experts? Other members include pediatricians, epidemiologists, pharmacists and pharmacologists, and a family physician - none of whom can be expected to be informed about the subtleties of HBV treatment.

The final complaint about government errors that hinder the management of HBV is the insistence on an elevated alanine aminotransferase (ALT) level before providing reimbursement for therapy. Despite very good evidence that ALT level is a poor predictor of outcome in HBV $(5,18)$, and that the current laboratory normal values are too high (26-28), some provinces continue to insist that they will only reimburse treatment in patients with elevated ALT levels, fibrosis notwithstanding. The concept that elevated ALT is an indication for therapy comes from the initial registration trials for both HBV and hepatitis $\mathrm{C}$ when an elevated ALT level was a criterion of entry in the study. With advances in knowledge and the ability to measure concentrations of virus in blood, the Food and Drug Admnistration no longer requires an elevated ALT level for registration studies. Although elevated ALT levels do indicate active disease, a normal ALT does not exclude active disease (28), and does not indicate the severity of fibrosis or the existence of cirrhosis. Yet, some provinces will not pay for any antiviral therapy - even in cirrhotic patients with high viral loads - if their ALT is not elevated.

There are hepatologists and infectious disease physicians in Canada who have the requisite expertise to help governments make the correct decision. These individuals, however, are rarely consulted either by the CDR or by organizations such as the Committee to Evaluate Drugs in Ontario. As a result, the state of HBV treatment in Canada is equivalent to that in so-called 'third-world' countries. Other jurisdictions where there is government reimbursement of drugs, such as the United Kingdom and Australia, have decided that entecavir and tenofovir are effective uses of public funds. Yet, in Canada, we come to a different decision despite having the same underlying data to consider. There is something wrong with a system that comes to such contrary decisions despite the evidence.

A large proportion of the HBV-infected population (perhaps $80 \%$ ) (8) are immigrants - a population that lacks any political voice. Contrast this with the HIV lobby, which is extremely well-organized and has huge political 'clout'. For how many HIV drugs has approval or reimbursement been delayed or denied? Tenofovir is a glaring example of this double standard. Tenofovir is acknowledged to be an excellent viral-suppressive drug for HIV and, accordingly, the CDR recommended approval for this disease. How could the same drug that is equally useful in viral suppression for two separate diseases be approved for one condition and essentially rejected for the other? If we

\section{REFERENCES}

1. Marcellin P, Heathcote EJ, Buti M, et al. Tenofovir disoproxil fumarate versus adefovir dipivoxil for chronic hepatitis B. N Engl J Med 2008;359:2442-55.

2. Chang TT, Gish RG, de Man R, et al; BEHoLD AI463022 Study Group. A comparison of entecavir and lamivudine for $\mathrm{HBeAg}$ positive chronic hepatitis B. N Engl J Med 2006;354:1001-10.

3. Lai CL, Shouval D, Lok AS, et al; BEHoLD AI463027 Study Group. Entecavir versus lamivudine for patients with $\mathrm{HBeAg}$ negative chronic hepatitis B. N Engl J Med 2006;354:1011-20.

4. Sherman M, Peltekian KM, Lee C. Screening for hepatocellular carcinoma in chronic carriers of hepatitis B virus: Incidence and prevalence of hepatocellular carcinoma in a North American urban population. Hepatology 1995;22:432-8.

5. Iloeje UH, Yang HI, Jen CL, et al. Risk evaluation of viral load. Risk and predictors of mortality associated with chronic hepatitis B infection. Clin Gastroenterol Hepatol 2007;5:921-31.

6. Statistics Canada census data. <www.12.statcan.gc.ca/censusrecensement/index-eng.cfm> (Accessed on September 24, 2010).

7. Zhang J, Zou S, Giulivi A. Hepatitis B in Canada. Health Canada 27S3, 2001. Government of Canada. <www.hc-sc.gc.ca/ pphb-dgspsp/publicat/ccdr-rmtc/01vol27/27s3/27s3e_e.html> (Accessed on September 18, 2003). extend the HBV cirrhosis paradigm to HIV, then approval should only be given to HIV-positive patients who have advanced to full-blown AIDS. However, the disparity in this analogy is even more egregious: whereas AIDS can be brought under control and some semblance of normal immune status can be achieved with antiretroviral therapy, once cirrhosis has been established, there is an uncertain chance of reversal and virtually no chance of complete restoration of normal liver histology with long-term antiviral therapy. In other words, AIDS is reversible with treatment whereas HBV cirrhosis is often not.

Indeed, a search of the CDR website (www.cadth.ca/index.php/en/ $\mathrm{cdr} /$ ) reveals that not a single anti-HIV drug has been completely and permanently rejected, which is not the case for anti-HBV drugs (telbivudine being the prime example). Thus, there is a widespread perception among HBV treating physicians and many patients that drug-access decisions are often 'politically' influenced. An effective lobbying voice seems to sway policy. In Canadian drug-access policy, it really does seem that the 'squeaky wheel gets the grease'. How else can one explain the disparities between drug approvals for the same drug in different diseases?

Patients with $\mathrm{CHB}$ are not being adequately served by the current reimbursement models in most provinces. This must change. We are not advocating the Quebec model, where any physician can freely prescribe any of the antivirals. The experience with lamivudine shows that when nonexpert physicians prescribe antivirals for HBV, the results are highly variable, ranging from a high-level management equivalent to that of experts, to frankly inadequate management protocols that lacked any virological testing for resistance or clinical monitoring. The Alberta model, in which prescribing access is limited to specialists including hepatologists, gastroenterologists and infectious disease physicians, appears to work well and is the model that we recommend that other provinces adopt.

Immigrants and other high-risk groups, such as northern Aboriginals, sex-trade workers and 'street people, have no political voice. Therefore, we, the physicians who treat these diseases, must protest on their behalf. We hope that this article will bring the plight of these patients to official eyes, and that appropriate decisions are made and corrective actions are taken.

DISCLOSURES: Dr Sam Lee has consulted for Bristol Myers Squibb (BMS), Gilead, Janssen, Merck, Novartis, Pharmasset, Roche, Tibotec and Vertex. He has received research support from BMS, Gilead, Janssen, Merck, Roche, Novartis, Pharmasset, Roche, Tibotec and Vertex. He has had speaking engagements for BMS, Gilead, Merck and Roche. Dr Morris Sherman has received honoraria from Bayer, Bristol Myers, Gilead, Roche, Merck, Vertex and Tibtec.

8. Leber A, Sherman M. Estimation of immigration related chronic hepatitis B infection and hepatocellular carcinoma development in Canada from 1981-2006. Can J Gastroenterol 2008;23(Suppl A):22.

9. P Marotta, K Lucas. Management of hepatitis B: A longitudinal national survey - impact of the Canadian Hepatitis B Consensus Guidelines. Can J Gastroenterol 2010;24:537-42.

10. Sherman M, Shafran S, Burak K, et al. Management of chronic hepatitis B: Consensus guidelines. Can J Gastroenterol 2007;(Suppl C):5C-24C.

11. Moskovitz DN, Osiowy C, Giles E, Tomlinson G, Heathcote EJ. Response to long-term lamivudine treatment (up to 5 years) in patients with severe chronic hepatitis B, role of genotype and drug resistance. J Viral Hepat 2005;12:398-404.

12. European Association For The Study Of The Liver. EASL Clinical Practice Guidelines: Management of chronic hepatitis B. J Hepatol 2009;50:227-42.

13. Lok AS, McMahon BJ. Chronic hepatitis B: Update 2009. Hepatology 2009;50:661-2.

14. van Bömmel F, de Man RA, Wedemeyer $\mathrm{H}$, et al. Long-term efficacy of tenofovir monotherapy for hepatitis B virus-monoinfected patients after failure of nucleoside/nucleotide analogues. Hepatology 2010;51:73-80. 
15. Liaw YF, Sung JJ, Chow WC, et al; Cirrhosis Asian Lamivudine Multicentre Study Group. Lamivudine for patients with chronic hepatitis B and advanced liver disease. N Engl J Med 2004;351:1521-31.

16. Yuen MF, Seto WK, Chow DH, et al. Long-term lamivudine therapy reduces the risk of long-term complications of chronic hepatitis B infection even in patients without advanced disease. Antivir Ther 2007;12:1295-303

17. Di Marco V, Di Stefano R, Ferraro D, et al. HBV-DNA suppression and disease course in HBV cirrhosis patients on long-term lamivudine therapy. Antivir Ther 2005;10:431-9.

18. Chen G, Lin W, Shen F, Iloeje UH, London WT, Evans AA. Past HBV viral load as predictor of mortality and morbidity from HCC and chronic liver disease in a prospective study. Am J Gastroenterol 2006;101:1797-803.

19. Iloeje UH, Yang HI, Su J, Jen CL, You SL, Chen CJ. Predicting cirrhosis risk based on the level of circulating hepatitis B viral load. Gastroenterology 2006;130:678-86.

20. Mommeja-Marin H, Mondou E, Blum MR, Rousseau F. Serum HBV DNA as a marker of efficacy during therapy for chronic HBV infection: Analysis and review of the literature. Hepatology 2003;37:1309-19.

21. Buti M, Brosa M, Casado MA, Rueda M, Esteban R. Modeling the cost-effectiveness of different oral antiviral therapies in patients with chronic hepatitis B. J Hepatol 2009;51:640-6.
22. Robotin MC, Kansil M, Howard K, et al. Antiviral therapy for hepatitis B-related liver cancer prevention is more cost-effective than cancer screening. J Hepatol 2009;50:990-8.

23. Spackman DE, Veenstra DL. A cost-effectiveness analysis of currently approved treatments for $\mathrm{HBeAg}$-positive chronic hepatitis B. Pharmacoeconomics 2008;26:937-49.

24. Veenstra DL, Spackman DE, Di Bisceglie A, Kowdley KV, Gish RG. Evaluating anti-viral drug selection and treatment duration in HBeAg-negative chronic hepatitis B: A cost-effectiveness analysis. Aliment Pharmacol Ther 2008;27:1240-52.

25. Sherman M, Yurdaydin C, Sollano J, et al; AI463026 BEHoLD Study Group. Entecavir for treatment of lamivudine-refractory, $\mathrm{HBeAg}$-positive chronic hepatitis B. Gastroenterology 2006;130:2039-49.

26. Prati D, Taioli E, Zanella A, et al. Updated definitions of healthy ranges for serum alanine aminotransferase levels. Ann Intern Med 2002;137:1-10.

27. Shiffman ML, Diago M, Tran A, et al. Chronic hepatitis C in patients with persistently normal alanine transaminase levels. Clin Gastroenterol Hepatol 2006;4:645-52.

28. Lee JK, Shim JH, Lee HC, et al. Estimation of the healthy upper limits for serum alanine aminotransferase in Asian populations with normal liver histology. Hepatology 2010;51:1577-83. 


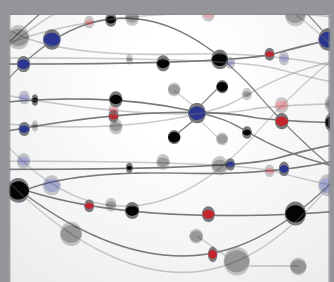

The Scientific World Journal
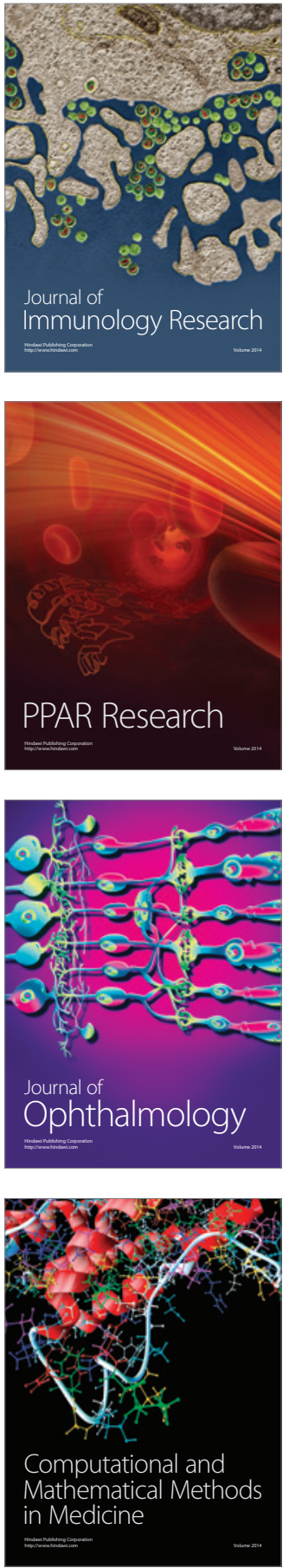

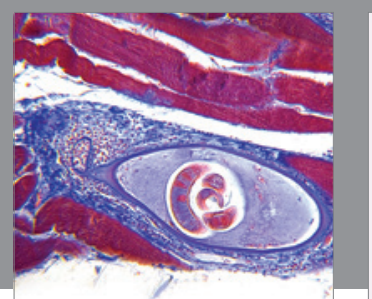

Gastroenterology Research and Practice

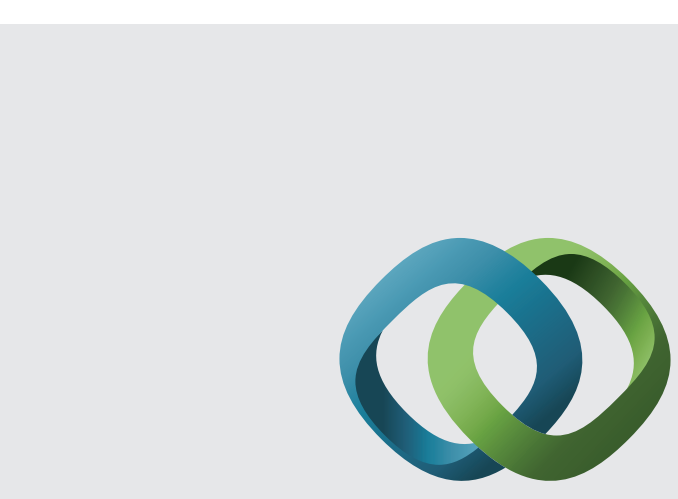

\section{Hindawi}

Submit your manuscripts at

http://www.hindawi.com
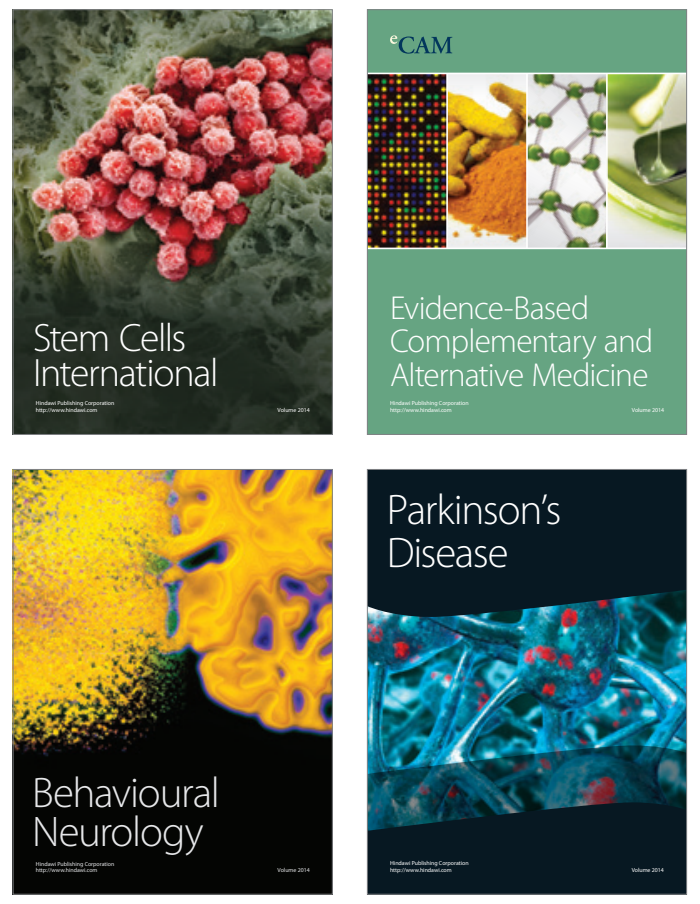
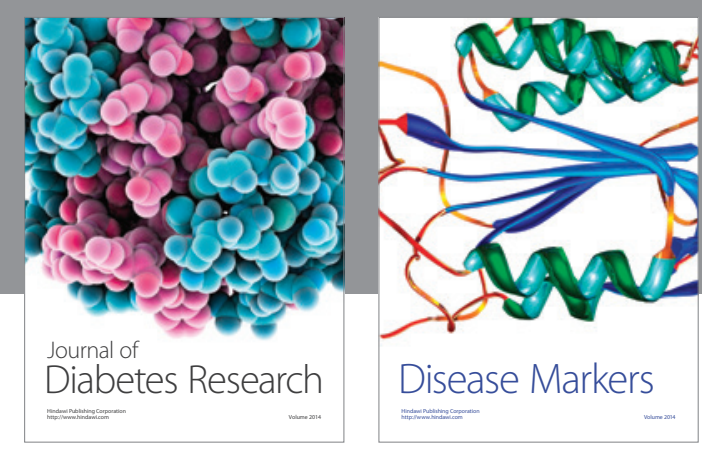

Disease Markers
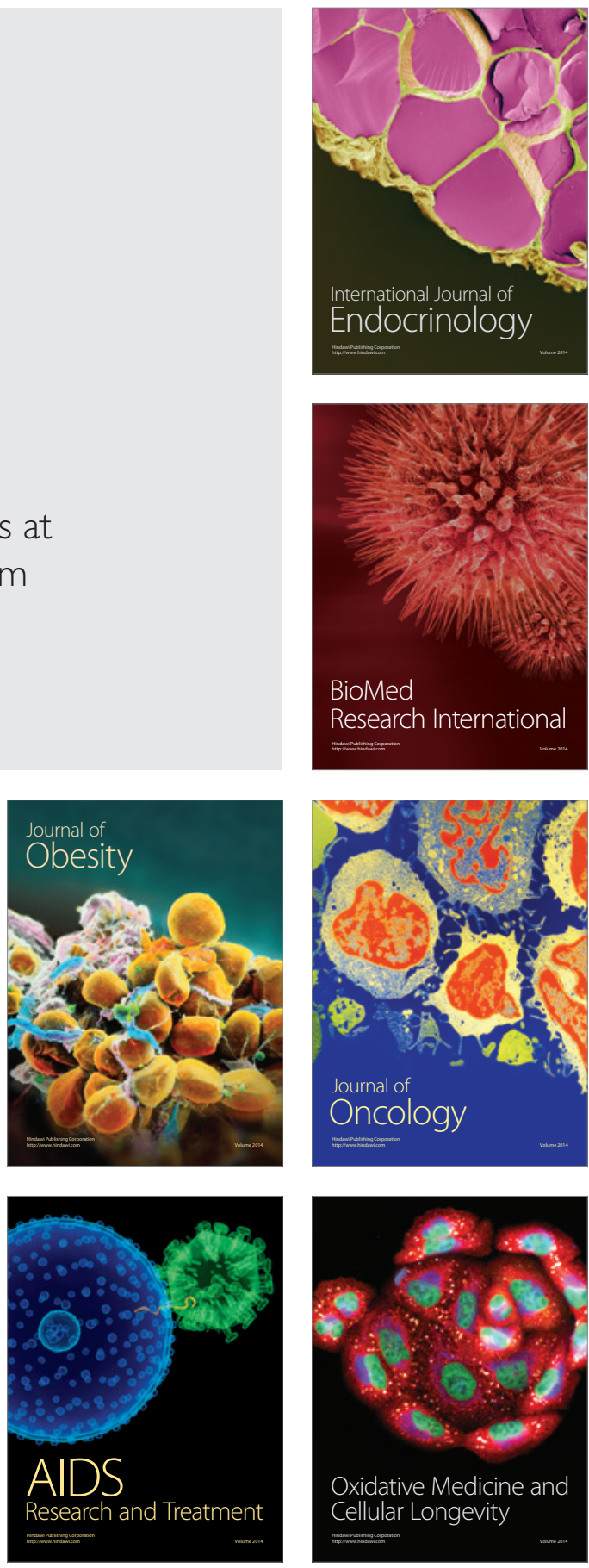